Int. J. Dev. Biol. 56: 437-445 (2012)

doi: $10.1387 / \mathrm{ijdb} .113458 \mathrm{ag}$

\title{
The Hydra model - a model for what?
}

\author{
ALFRED GIERER* \\ Max-Planck-Institute for Developmental Biology, Tuebingen, Germany
}

\begin{abstract}
The introductory personal remarks refer to my motivations for choosing research projects, and for moving from physics to molecular biology and then to development, with Hydra as a model system. Historically, Trembley's discovery of Hydra regeneration in 1744 was the beginning of developmental biology as we understand it, with passionate debates about preformation versus de novo generation, mechanisms versus organisms. In fact, seemingly conflicting bottom-up and top-down concepts are both required in combination to understand development. In modern terms, this means analysing the molecules involved, as well as searching for physical principles underlying development within systems of molecules, cells and tissues. During the last decade, molecular biology has provided surprising and impressive evidence that the same types of molecules and molecular systems are involved in pattern formation in a wide range of organisms, including coelenterates like Hydra, and thus appear to have been "invented" early in evolution. Likewise, the features of certain systems, especially those of developmental regulation, are found in many different organisms. This includes the generation of spatial structures by the interplay of self-enhancing activation and "lateral" inhibitory effects of wider range, which is a main topic of my essay. Hydra regeneration is a particularly clear model for the formation of defined patterns within initially near-uniform tissues. In conclusion, this essay emphasizes the analysis of development in terms of physical laws, including the application of mathematics, and insists that Hydra was, and will continue to be, a rewarding model for understanding general features of embryogenesis and regeneration.
\end{abstract}

KEY WORDS: pattern formation, lateral inhibition, tissue evagination, Trembley, Caspar Friedrich Wolff

\section{How a physicist gets involved with Hydra - some personal reminiscenses}

In the last decades, there were very stimulating bi-annual meetings of Hydra researchers, initiated by Charles David, in the castles of Reisensburg and of the Evangelische Akademie in Tutzing at beautiful Lake Starnberg. At each conference there was an evening lecture, usually unpublished, dedicated to more general topics, and speakers were encouraged to include personal reflections. The editor of this special issue, Brigitte Galliot, has kindly invited me to adapt my contribution for this special edition on Hydra.

Let me begin with a few remarks of a personal nature on motives for the orientation of scientific interests that led me into research on Hydra. I studied physics from 1946 onwards, without the slightest trace of biology. There were two somewhat diffuse motivations when I was a teenager at High School that eventually lured me into physics: a fascination with physical chemistry: "what is the physics of the periodic system and the chemical bond?" and a vague notion that Heisenberg was a genius. When rumors spread that he would settle in Göttingen in 1946, I tried everything I could to enrol at Göttingen University and to find a way into his newly founded Max Planck Institute of Physics. Heisenberg was very stimulating for young scientists, in several ways. He was willing to take young people seriously right at the start, though not always later. He made it clear that the best phases in science are romantic phases such as he had experienced in the twenties, when quantum mechanics was invented; and philosophical aspects of science were one of the main areas of discussion (see Heisenberg, 1969) - Schrödinger's spooky cats, half alive, half dead according to quantum indeterminacy, roamed the institute.

My thesis advisor, Karl Wirtz, although a nuclear physicist, was also fascinated by the physical foundations of biology as a result of his time in Berlin; Timofejef was there. He confessed to me that, if he were young, he would not work on nuclear reactions but would study proteins. I worked on protons jumping across hydrogen bonds, vaguely motivated by the importance of such bonds in proteins, the substance of life as most of us still thought at that time. I got hold of Linus Pauling's book "The nature of the chemical bond"

\footnotetext{
*Address correspondence to: Alfred Gierer. Max Planck Institute for Developmental Biology, Spemannstrasse 35, D - 72076, Tübingen, Germany. e-mail: alfred.gierer@tuebingen.mpg.de-Web: http://www.eb.tuebingen.mpg.de/gierer
} 

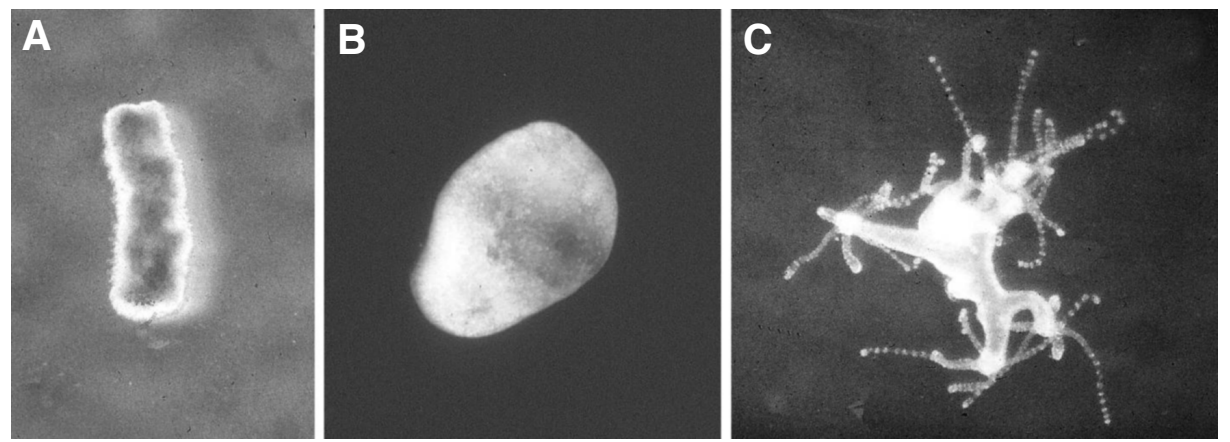

our advocate putting the case for Hydra was Werner Müller, who worked in the Zoology department at Tübingen University. We decided on Hydra and, soon after that, Richard Campbell, visiting us from Irvine, was wading into muddy ponds all over the Schoenbuch forest to search for good specimens. Howard Lenhoff sent us Kanaev's book on the history and biology of Hydrathat he had edited, with the most warm-hearted wishes for our new group, and Pierre Tardent provided us with Hydra attenuata and also with generous

Fig. 1. Regeneration of Hydra from aggregated cells. Hydra cells form random aggregates; ejected from a pipette (A), they sort out to generate a hollow structure with ectoderm and endoderm typical of Hydra tissue (B). Then, new heads are formed, grow out (C) and eventually separate into normal polyps. Such regeneration is prototypical for de novo pattern formation in development and its modelling by theoretical analysis (see Meinhardt 2012, Fig. 5).

(Pauling, 1946) and there I had my new hero, especially after I heard him lecture, in 1952, on the newly discovered alpha helix (Pauling et al., 1951).

After getting my $\mathrm{PhD}$ in Göttingen, I was lucky enough to be awarded a Fulbright fellowship, though not lucky enough to be assigned to Caltech where Pauling worked. Instead, I got assigned to MIT because I was a physicist and not a chemist. Altogether, it was a rewarding year. After returning to Germany, I worked at the newly founded Max Planck Institute for Virus Research in Tübingen, which turned out to be an ideal place for a young physicist interested in biology. At the time Tobacco Mosaic Virus became one of the model systems for studying basic biological processes. Our work was on the role of the viral nucleic acid as genetic material (Gierer and Schramm, 1956). In fact, the fifties and the early sixties were the romantic decade of molecular biology (often compared, for good reasons, with the golden twenties when quantum physics was developed), when so many exciting facts emerged from laboratories in distant places, often within months rather than years. The virus work got me an early appointment as head of a new division of molecular biology in our Institute; I continued with work in this field for a few years, the next topic being polyribosomes. By 1963, the central dogma of molecular biology was established: DNA makes RNA and RNA makes proteins. Fine, but what next? Perhaps even: now what?

Such questions encouraged a radical change in my research interests and lead to my taking up work on the developmental biology of multicellular organisms. This field was not yet fashionable in the sixties. It had an old-fashioned flavour, said to be frustrating by lack of specificity of effects, such as those of Spemann's organizer. To be sure, we had at first the attitude that it might now be up to us molecular biologists to tell those embryologists what their field was all about, with all their fuzzy notions - morphogenetic fields, polarity, competence, gradients and whatnot. But very soon our wonder at the marvellous, if holistic and phenomenological world of embryology reached the highest levels, and I became particularly intrigued with what is perhaps the most holistic of the problems, the generation of spatial patterns. Anyhow, it became more and more obvious that it was up to us molecular biologists to become a little more modest and, first of all, to learn from them, the development people.

Experts representing various biological systems were invited, and and Ekkehard Trenkner - who were postdocs themselves not long thereafter, joined me in Tübingen in establishing our Hydra project. Subsequently, other colleagues came and worked with us on the project at various stages. We were intrigued by the problem of how spatial patterns are newly formed in tissues, for which Hydra regeneration is such a clear and spectacular model. We tried to push regeneration to the limit by studying the formation of animals from aggregates of previously isolated cells (Gierer et al., 1972; Fig.1). We searched for activating and inhibiting factors affecting head formation and other patterning processes (Schaller, 1973; Berking, 1977); and we studied the quantitative regulation of stem cell renewal versus cell differentiation (David and Gierer, 1974). There was an initial romantic phase of enthusiasm, followed by a somewhat lengthy incubation phase before eventually results were achieved and published. Thereafter, the members of our original group were able to convert their achievements into job offers from various distinguished institutes and were very successful in developing their own projects. Experimentally, my division in Tübingen has changed orientation in the course of the seventies, tending more in the direction of neuroembryology.

In parallel with all this, Hans Meinhardt and I had started a program on theoretical biology, with particular emphasis on the formation of spatial patterns; a program, which has continued up to the present (Meinhardt, 2012). The central question is, how physical laws and processes can account for the de novo production of spatial patterns in cells and tissues starting from near-uniform conditions? Obviously, a full explanation requires knowledge of the molecules involved, but this would not be sufficient. Even a complete list of all these molecules would not in itself explain the resulting spatial structure, say, of a mouse. In general, pattern formation is a systems' feature. A cloud is condensed water, a snowflake is frozen water, $\mathrm{H}_{2} \mathrm{O}$; there are no mysteries about the molecules involved and yet this fact is not enough to make any of us understand the form of clouds or the beauty of snowflakes. Ultimately, it is a combination of material knowledge and systems theory that is required. Likewise, investigating biological pattern formation is a two-way process - bottom up starting from interactions of molecules and cells, and top down starting from phenomena, such as patterns and proportions. And since the two approaches are often correlated with different outlooks of the scientists involved, not excluding their philosophical and metaphysical ideas, 
it is not surprising that their coming together may be retarded by psychological obstacles.

\section{Mechanisms, organisms and the origins of developmental biology in the $18^{\text {th }}$ century}

Different mental attitudes of this type can be traced far back into the history of science, and I would like to follow, and comment on a few such historical traces at this point. In a sense, Aristotle may be considered the founder of biology as a science, because it was he who first postulated that reproduction and metabolism - and not features such as breathing - define life. And he took life processes, with their holistic and goal-directed features, as a model for physics as a whole; here was harmony, not conflict between physics and biology. Only in modern times, when Galilei, Kepler and Newton laid the foundations of modern physics with mathematical laws governing the movements of material bodies did the relation between mechanisms and organisms, between the living and the non-living world, become such very challenging and puzzling problems. Only then did the question arise: How can a physics developed exclusively from studies in the inorganic world claim validity for all events in space and time, which do, after all, also contain living organisms? Is the living body just a machine, as Descartes postulated, with perhaps some vague allowance for effects of the soul mediated in man by a small part of the brain, the pituitary gland? Is the seemingly new formation of the organism in each generation just an illusion, whereas actually it pre-existed even in the egg? Does this mean that all future generations of an organism are contained in the body, like the ever-smaller Russian dolls within dolls? Is there nothing but unfolding of pre-existing, invisibly small structures? If so, this would imply that there is no real development and then, of course, no developmental biology, and no developmental biologists either.

It appears rather strange to us that this doll-within-doll concept
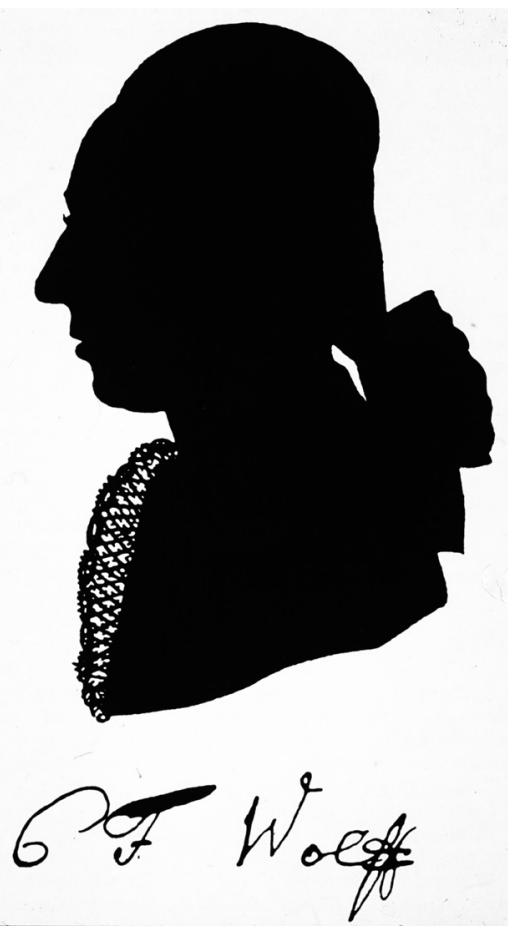

was a dominant theory in the $18^{\text {th }}$ century, propagated especially by Bonnet and Haller. The alternative is that there is real epigenesis, as Aristotle had postulated more than 2000 years earlier; but if this is so, does it require new physical laws or extraphysical concepts? Yes, was the assumption of one of the early pioneers of modern developmental biology in the $18^{\text {th }}$ century, Caspar Friedrich Wolff, but the main achievement of his work was empirical: His PhD thesis, entitled "Theoria generationis" (Wolff, 1759) strongly supported de novo generation. There is only one extant picture of Caspar Friedrich Wolff (Fig. 2). Characteristic for his thorough experimental research is a beautiful drawing of the 36 hours chick development he observed with a microscope and reported in his dissertation (Fig. 3). Wolff insisted that the visible features and sequences of pattern formation during chick embryogenesis were inconsistent with unfolding of pre-existing structures. Unfortunately, it was the dogmatic preformationist Haller who dominated the scientific establishment of the time, making life difficult for Wolff (see Roe, 1982). Eventually he accepted an invitation from Catherine the Great to become a member of the Russian Academy in Sankt Petersburg. Only after the turn of the $18^{\text {th }}$ century was Wolff rediscovered, especially by Goethe, who wrote about "our outstanding compatriot, whom a dominant school with which he could not agree had driven out of his native country" (Goethe, 1817).

Fifteen years before Wolff presented his "Theoria generationis", Abraham Trembley had published his discoveries on the regeneration of Hydra: an animal dissected into two pieces will develop into two complete animals (Trembley, 1744). These findings were communicated almost immediately by Réaumur to the Academie of Sciences in Paris (Réaumur, 1741). Indeed Reaumur repeated the experiment himself, and he found that virtually any small seemingly uniform section of body tissue developed into a complete polyp. Then Rösel von Rosenhoff, the editor of 'Insektenbelustigungen', 'Amusement about Insects', an early version of a popular scientific periodical, refined these findings. In the volume of 1755, he described his discovery that random aggregates of the tiniest pieces of Hydra tissue he could obtain by cutting the polyp would eventually regenerate into multi-headed Hydra monsters (Rösel von Rosenhof, 1755).

The impact of Trembley's discovery sounds almost unbelievable in our times. It is described in Kanaev's book on Hydra, in the edi-

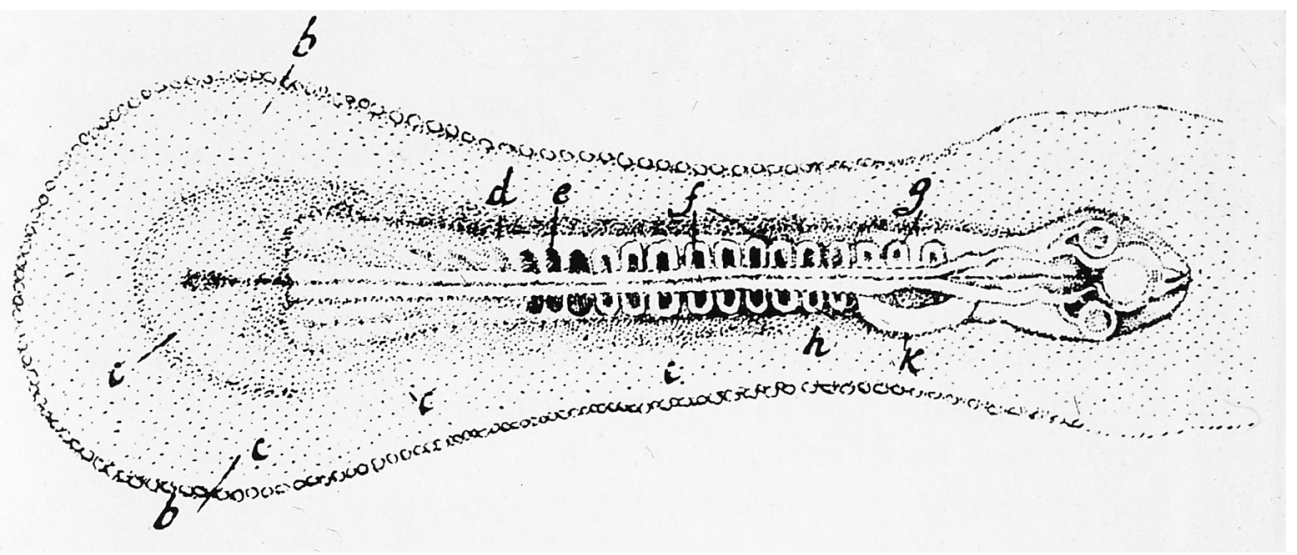

Fig. 2 (Left). Caspar Friedrich Wolff (1734-1794).

Fig. 3 (Right). Early stage of chick development. Drawing in the dissertation by Caspar Friedrich Wolff "Theoria Generationis," Halle, 1759. 


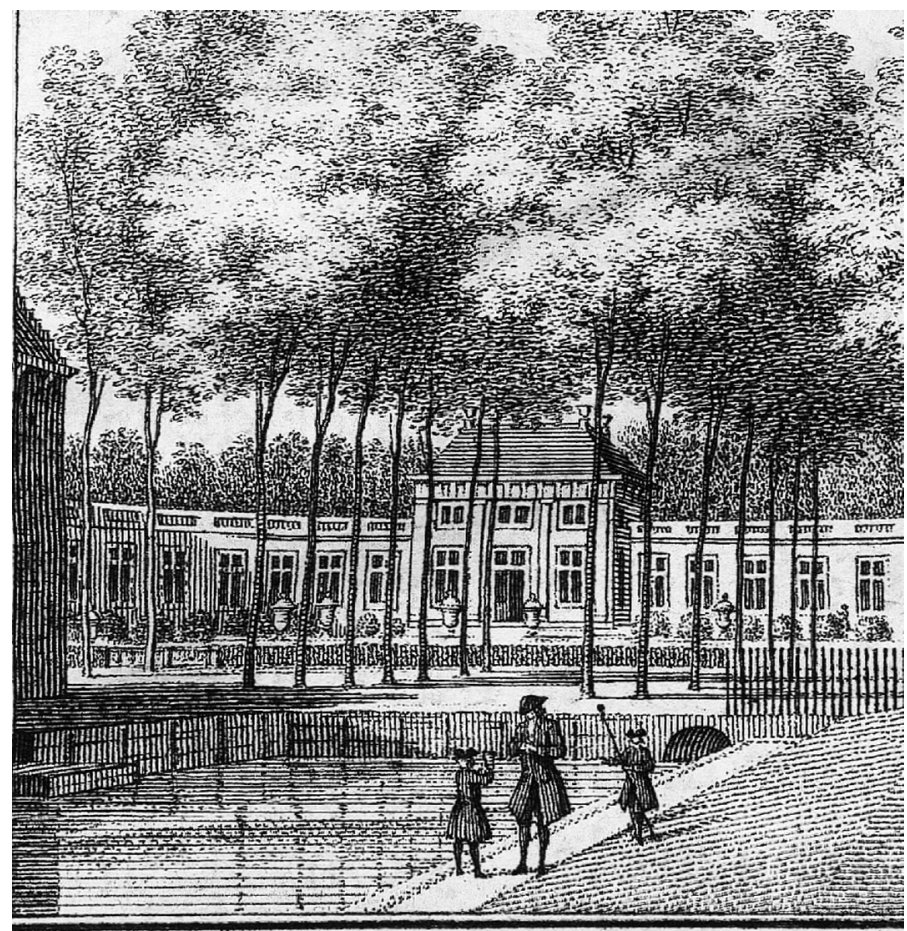

C.Pront de. .22No. 2744 .

Fig. 4. Abraham Trembley (1710-1784). A vignette showing Trembley with two pupils on the way to fishing Hydra from a pond is on the first page of the first memoir in his centennial book on polyps "Mémoires pour l'histoire des polypes d'eau douce" of 1744 .

tion prepared by Howard Lenhoff that I have already mentioned. In the $18^{\text {th }}$ century, regenerating polyps were talked about in literary, philosophical and theological circles. Embassies considered it their duty to keep their governments informed about progress in Hydra research, and an observer declared that the discovery of polyp regeneration and that of electricity were the two outstanding achievements of the $18^{\text {th }}$ century. But even with less enthusiasm, giving modern scientific skepticism its due, it is hard to overlook the importance of Trembley's work (Ratcliff, 2012). He can be considered the first experimental developmental biologist in the history of science. His marvellous book makes good reading even today, which can hardly be said about most other works of his time. And his attitude towards science was also most remarkable. In the last pages of his book, he writes "what we actually know is still very little in relation to the innumerable wonders of nature. The best method to understand known facts is to discover new facts. Nature is to be understood with the help of nature, not by our preconceptions which are too limited for grasping such great objects of research as a whole."

Fig. 4, taken from Trembley's book of 1744, shows him as a private tutor with two pupils on the way to fishing polyps from a pond. By the way, Trembley did not go on working on Hydra for long; he changed fields and became a prominent author on child development and education.

\section{On the physical basis of biological pattern formation}

Thus, Caspar Friedrich Wolff and even more Abraham Trembley left us with the question of how the generation of patterns in biological systems, i.e. the development of spatial order by internal processes within cells and tissues, can be explained on a physical basis. Many scientists, up to the time of Spemann in the thirties, had thought or guessed that this might not be possible at all. A new physics, or some extraphysical principles might be required. However, we now know that this is not the case. Combinations of rather conventional molecular interactions and movements, even passive movements by diffusion, are good at pattern generation. This was discovered by A. Turing in 1952. He designed and discovered equations for reaction-diffusion systems that generate spatial concentration patterns starting from near-uniform initial distributions (Turing, 1952). His deduction was based on the analysis of destabilization of uniform distributions giving rise to concentration waves of certain wavelengths. Thus, normal chemical reactions in liquid media are able to generate concentration patterns. Does this have biological significance for morphogenesis? To answer this question it is necessary to explore conditions for pattern formation in molecular terms and, most important, to explain the impressive self-regulatory features of developing biological systems, such as proportion regulation - the adaptation of the size of a part to the size of the whole. With these aims in mind, Hans Meinhardt and I proposed in the seventies a theory of pattern formation based on two concepts: autocatalytic activation and lateral inhibition (Gierer and Meinhardt, 1972). Our starting point was a line of thought originally introduced into the field of pattern recognition by Hartline, Wagner and Ratliff (Hartline et al., 1956) and by Kirschfeld and Reichardt (Kirschfeld and Reichardt, 1964) in our neighbouring Institute for Biological Cybernetics.

The key concept is lateral inhibition. Let us draw an egg (Fig. 5A). Does our drawing really represent an egg? No, it is the contour of an egg. The image of a real egg on the retina looks different (Fig. $5 \mathrm{~B})$. To obtain the contour, the local intensities projected onto the retina are processed there by local activation in conjunction with an inhibitory effect extending into the environment of activation. Inside the bright area, high inhibition cancels high activation; inside the dark area, low inhibition cancels low activation. But at the edge, high activation is not cancelled because the inhibition extending from the neighbouring dark area is low. Therefore the edge is enhanced, and the contour of the egg is outlined. This mechanism is well established in both psychophysical and neurobiological terms, and it shows an intriguing general feature: it allows for the generation of striking patterns, starting with very shallow ones.

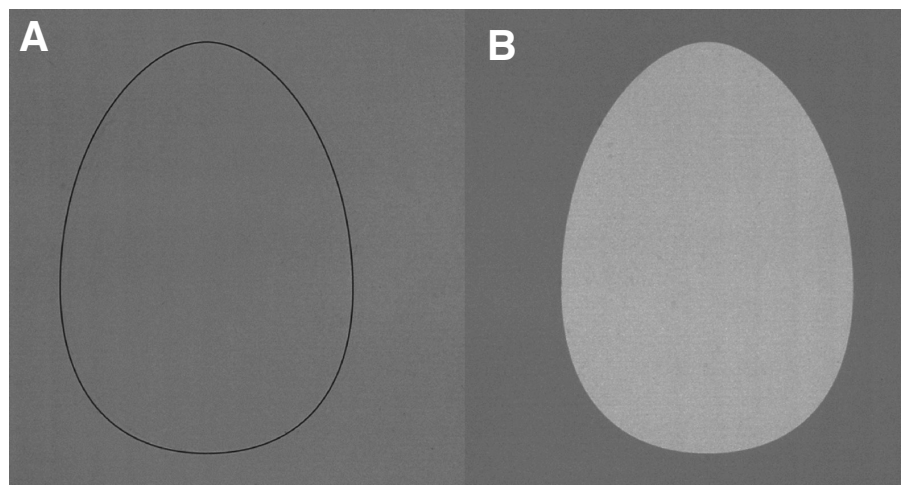

Fig. 5. Lateral inhibition in pattern recognition. Drawing an egg means drawing the contour of an egg (A) which is abstracted from the primary image of the egg on the retina (B) by mechanisms involving lateral inhibition. 

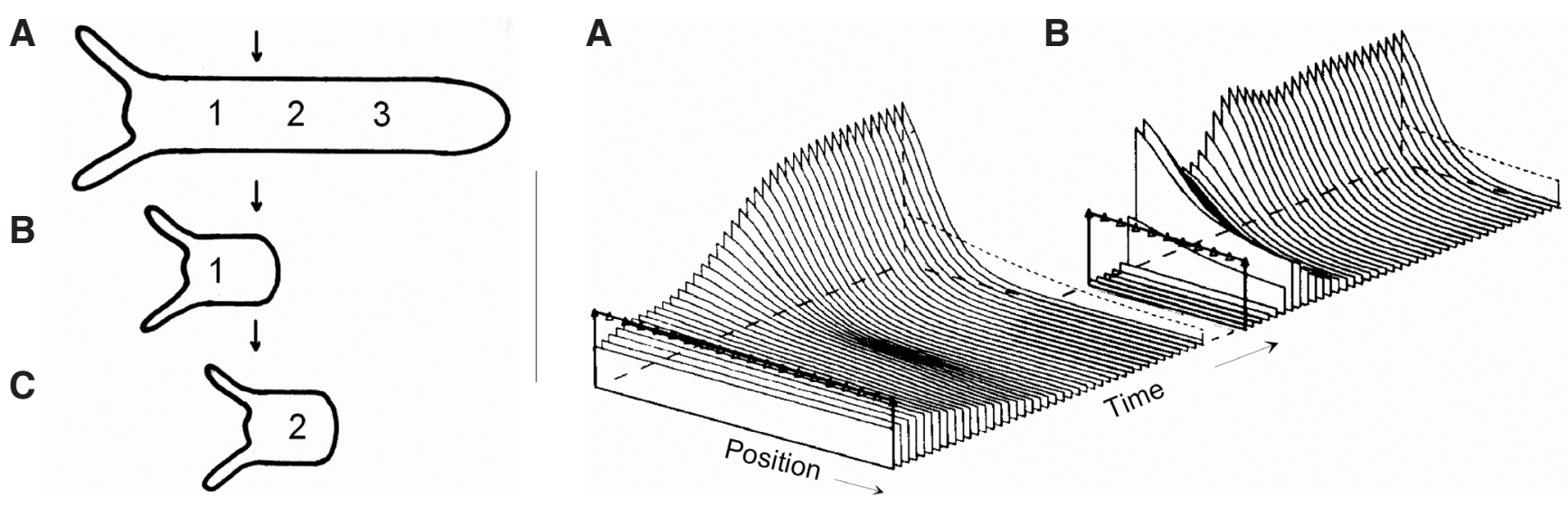

Fig. 6 (Left). De novo pattern formation in Hydra regeneration. Any section cut from the gastric column of Hydra regenerates an animal with head and foot. Thus, the same part of the body column (arrow) may produce nothing (A), a foot (B), or a head (C), depending on whether and where the section is cut. It follows that no pre-existing local property of the tissue (such as a polarity-defining gradient determining the orientation of regenerates) can per se decide where a head is formed; this can be decided only by the formation of a new morphogenetic gradient after the onset of regeneration.

Fig. 7 (Right). Pattern formation by autocatalysis and lateral inhibition. The computer simulation (A) shows the formation of a striking pattern of activator (modelling a morphogenetic gradient specifying positional information, for instance for head formation in Hydra tissue) starting from uniform initial distributions except for a shallow graded source (line with triangles) underlying the polarity of the tissue. This polarity determines only the orientation but not the form of the activator pattern which is newly produced in a self-regulating manner and rather robust against distortions. Sections cut from (A) regenerate, with conserved orientation, a new pattern (B) in agreement with de novo pattern formation in dissected Hydra (fig. 6).

For instance, our eye can recognize edges of areas that are very slightly less grey than the areas surrounding them. This can be experienced directly by looking at the borderline between the left (A) and the right $(B)$ part of Fig. 5.

We applied the principle of lateral inhibition in modified form to pattern formation in the course of development, now of course with molecules interacting and moving instead of neurons firing. Our theory demonstrates that patterns are newly formed by local self-enhancing reactions which are controlled, spatially limited, and disciplined by a wider ranging inhibitory effect. The ranges of activation and inhibition are defined by the mean distance between production and decay or removal of a molecule. Starting from an initially near-uniform distribution, local activation is self-enhancing, but activation at one location can proceed only at the expense of de-activation elsewhere. Non-linear interactions are required for the generation of reproducible, stable patterns. Power laws for the order of reactions can be introduced to analyse general conditions for which type of systems would generate patterns and which would not; one of the simplest ones has often been used as a model, but the general conclusions would apply to other versions as well.

Hydra regeneration is a particularly clear example of de novo pattern formation and helps to get the logic straight (for review see Gierer, 1977a; Meinhardt, 1982). What do we want to explain? Any isolated section of the body column regenerates an animal with head and foot (Fig. 6). The orientation of the pattern is determined by the polarity of the regenerating tissue. We attribute this to the slope of a shallow source gradient of compounds involved in pattern formation, extending across the tissue from head to foot. However, the absolute value of this graded cue cannot determine where a head is formed - because one and the same part of the body column, with the same local level of the polarity-defining graded source can lead to the formation of a head, or a foot, or nothing, depending on how the section is cut. In other words: the pattern formed is oriented by previous polar cues. But aside from that one single bit of information - deciding on orientation to the left or to the right - the pattern itself, namely a head-activating morphogenetic gradient, is newly formed. It is such internal de-novo-pattern generation that the conjunction of activation and inhibition is capable of explaining, as shown by computer simulations (Fig. 7). The resulting pattern is self-regulating and is a product of molecular interactions and movements within the initially near-uniform tissue; it requires no dolls-within-dolls, however hidden. And this type of mechanism gives rise to the striking regulatory features that are so characteristic of biological development, ensuring reliability despite complexity. In particular, details of initial conditions don't matter. Regeneration is possible, as is induction, inhibition and, under certain conditions, proportion regulation. Not only gradients but also symmetrical and periodic distributions, stable or pulsing in time can be generated in this manner (for review see Gierer, 1981; Meinhardt, 1982; Meinhardt and Gierer, 2000).

I would like to mention two general aspects. One is the relation of our activation-inhibition approach, which is directly linked to biological developmental regulation, to Turing's Fourier-type stability analysis, implying the detection of spatial wavelengths of distributions towards which the uniform distribution is unstable. It can be shown that the mathematical content of the lateral inhibition concept, and that of Fourier-type analysis are closely related; but the demonstration is by no means straightforward. It takes time and patience to prove (Babloyantz and Hiernaux, 1975; Granero et al., 1977; Gierer, 1981). Indeed, the combination of autocatalytic activation and long range inhibition can be demonstrated mathematically to be essential, to be the only mode of pattern generation for the simplest two factor case.

But what about pattern formation in systems with more of two variables? This, after all, is the biologically most likely case: feedback loops, for instance, consisting of a chain of reactions. Consider schemes of, say, seven or ten reactions. What is now our criterion for pattern formation? We might think of collecting those compounds that have autocatalytic effects and analysing them for themselves, but this leads nowhere. For instance, activation can 


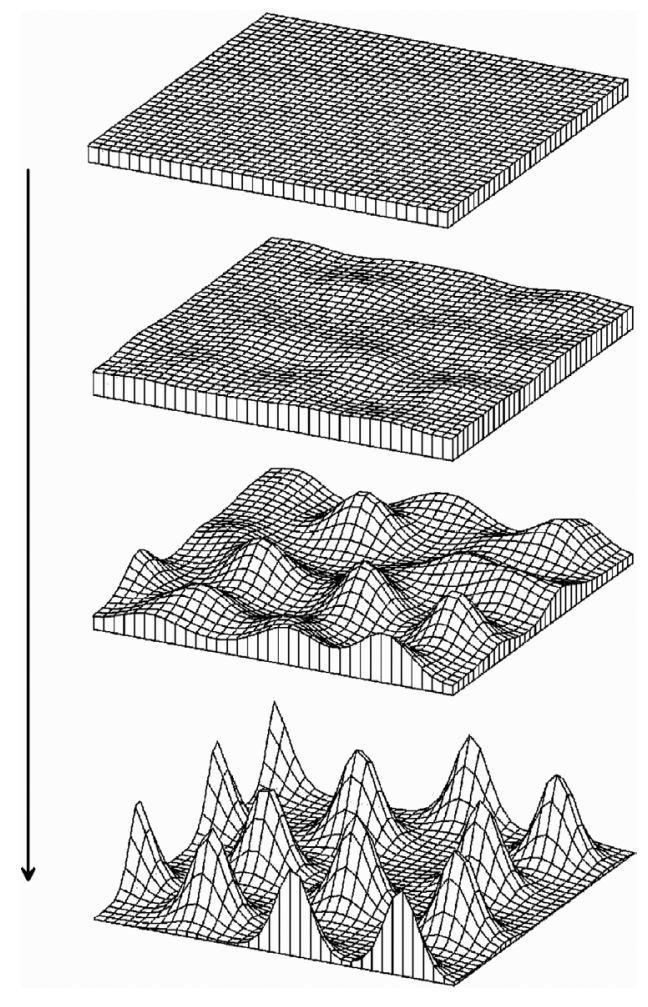

Fig. 8. Formation of multiple peak patterns. Even if initiation of pattern formation occurs by random fluctuations, the pattern of peaks formed, though irregular, is not completely random; due to lateral inhibition, small distances are avoided, giving rise to a 'granular' texture.

result just from inhibition of inhibition, allowing for pattern formation even if there is not a single directly activating reaction. The more adequate approach is a different one: apply the lateral inhibition concept from the outset. Begin the analysis by sorting the molecules involved into short-range ones on the one hand, and those subject to wider distribution in the tissue on the other. Then, check whether the short-range subset, taken together, is in itself autocatalytic as a system, and whether the long-range molecules prevent an overall autocatalytic explosion. In this way, the concept "pattern formation by the interaction of activation and inhibition" can be generalized into multi-component systems with activation and inhibition as features of subsystems rather than of individual substances. And yet, the basic regulatory capabilities that characterize biological development are maintained (Gierer, 1981). Applied to Hydra it means that satisfactory physical explanations of the processes of pattern formation would require detection of those molecules that operate more locally, in order to demonstrate the autocatalytic features of this subset, as well as the detection of inhibiting effects of long-range components. In view of exciting new results, such as those on wnt and brachyury genes, it appears that such a consistent physical account of de novo pattern formation may not be out of reach for research on Hydra.

Now, after much mathematics and systems theory, let me turn to some more general issues: What is the relation between the activation-inhibition type of biological pattern formation and other processes of generating structures? Self-enhancement is involved in many systems, in the for- mation of crystals and sand dunes, for instance, and of galaxies and stars. It is involved in socioeconomic processes, such as the formation of towns, and in psychological processes - success generates success, frustration leads to even more frustration. It might be involved in the generation of socioeconomic inequalities.

Further, there may be unexpected relations between pattern formation and pattern recognition, beyond edge enhancement. Fig. 8 shows a multiple peak pattern formed following initiation by random fluctuations. Though the resulting pattern is irregular, it is not truly random; it shows a "granularity" avoiding small distances due to the effects of lateral inhibition (Meinhardt and Gierer, 1974). A biological example of this type of texture is the surface of the Fugu-fish (Fig. 9A), a potentially poisonous Japanese delicacy for gourmets living up to the rule "no risk, no fun". It is remarkable that our visual system is capable of immediately perceiving textures of this type (Julesz, 1965). This can be seen by looking at Fig. 9B, showing distributions of spots generated by computer: the granularity in the central area excludes small distances between spots while in the outer areas the density of the spots is the same but with a truly random distribution. The observer recognizes immediately, without conscious thought, that the texture in the center is distinct. In much more general terms, the relation between mechanisms of pattern formation and the aesthetics of patterns is illustrated in Hans Meinhardt's book 'The algorithmic beauty of sea shells' (Meinhardt, 2003) explaining the development of beautiful visual patterns by formally beautiful developmental mechanisms.

\section{On morphogenetic fields, real form and the role of mathematics}

Pattern formation, as I have discussed it up to now, concerns invisible concentration patterns of morphogenetic substances. How do they elicit morphogenesis proper, that is, the generation of real form? Real form means curvature, for instance, that resulting from evagination of initially flat cell sheets as in the case of budding Hydra. Cytoskeleton, intercellular junctions, cell surface molecules, and intercellular matrix, all have their roles. Again, some general systems' aspects may be helpful in studying and understanding the processes involved.
A

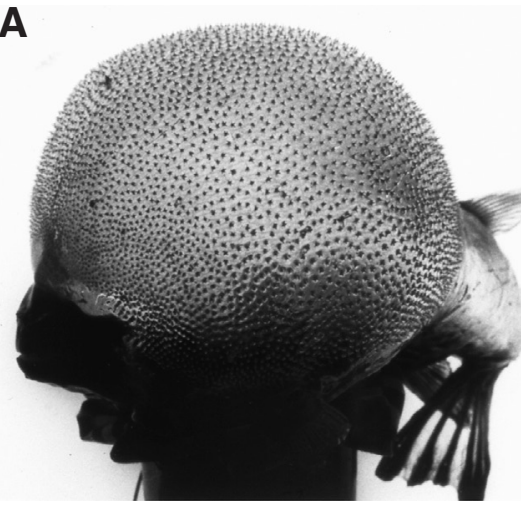

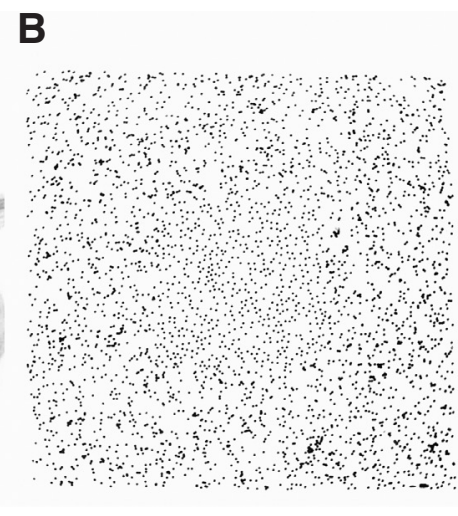

B
Fig. 9. Pattern formation and pattern recognition of granular textures. The surface of Fugu-fish (A) shows a 'granular' texture corresponding to the model calculation of Fig. 8 for pattern formation by activation and lateral inhibition. This type of texture, which can be seen at the center of $(\mathbf{B})$ is recognized immediately by the pattern recognition system of our brain and distinguished from truly random distributions of spots with the same average density, as in the outer parts of (B). 
A

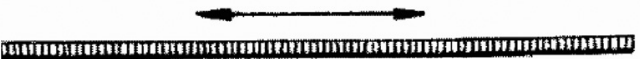

B

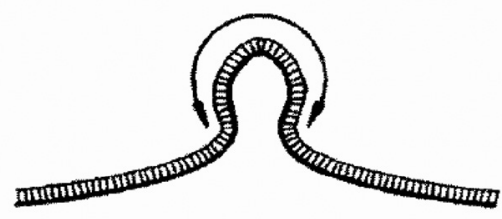

C

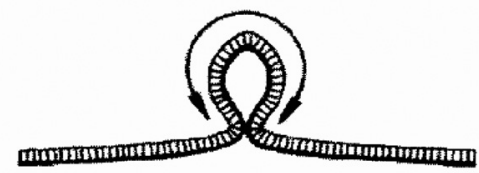

Fig. 10 (Above). Stability and evagination of cell sheets. Stability of a cell sheet requires non-linear cell interactions avoiding clumping as well as dissociation. Activation of part of the sheet by a morphogenetic field (double arrow) (A) may cause bending moments, curvature and thus evagination of the sheet $\mathbf{( B , C )}$.

Fig. 11 (Right). Generation of form, modeled on the basis of shell theory. Activation of a central area of the sheet is assumed to induce bending moments and evagination. The figure shows computer simulations of sections cut along the axis of rotationally symmetric structures.

To begin with, in terms of physical cell interaction, it is not that difficult to envisage a cell sheet evaginating upon local activation; the more difficult issue to grasp is why there is a stable cell sheet in the first place. If cells like contacts with other cells, they clump. If not, they segregate. A cell sheet, however, is a compromise, and this requires non-linear interactions. Cells that form sheets do like contact between cells, but not too much of it; they want to see the waterfront as well; and cells are polar, giving rise to cell sheets differing in and near their two opposing surface areas (Fig. 10A). Once the conditions of cell sheet stability and polarity are met, however, almost any local morphogenetic signal could change bending moments, thus giving rise to local tissue evagination (Fig. 10 B,C). And this applies also for multiple sheets made up of ectoderm, mesoglea, endoderm. Thus, understanding the stability of this arrangement in the first place is essential for understanding morphogenesis (Gierer, 1977b; 1981).

There is a non-molecular aspect of evagination that I would like to mention briefly - the intricate interaction of the curvatures of the two surface dimensions upon evagination. We have adapted and applied shell theory for computer models of such processes. In Fig. 11 computer simulations are shown of rotationally symmetric evagination or invagination of cell sheets, induced by a spot of activation causing a local bending moment to arise there. Shell theory is the theory used by architects to construct thin curved concrete roofs covering wide areas; the difference is that in our biological applications the emphasis is not on tangential forces but on bending moments, which architects avoid like hell because they would cause their roofs to collapse.

And this reference to shell theory brings me back to an interesting historical episode I would like to recount. The first application of mathematical mechanics to curved roofs was in the middle of the $18^{\text {th }}$ century, about the time Hydra regeneration was discovered
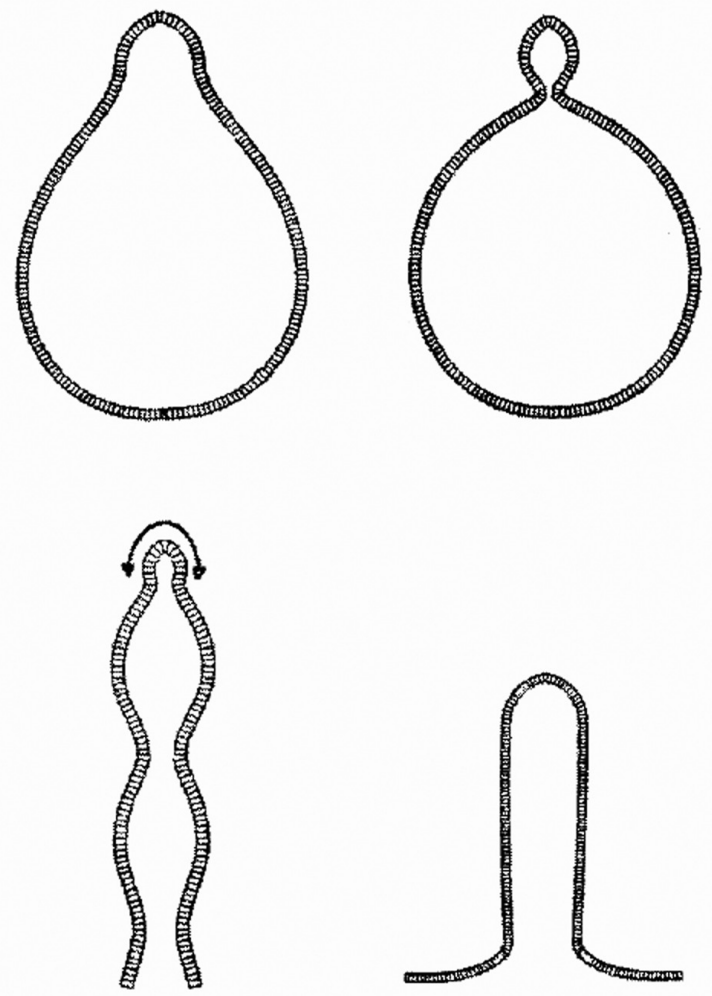

by Trembley. At that time, dangerous cracks appeared in the base of the cupola of St. Peter's Basilica in Rome (Fig. 12). Methods of saving the building were proposed, involving clumsy reinforcements of the walls or removal of the beautiful lantern that Michelangelo had placed on top of the cupola. At this stage, Pope Benedict XIV asked three mathematicians of the Jesuits' Collegio Romano to look at the problem from a theoretical mathematical point of view (Boscovich et al., 1743). They proposed the addition of iron chains around the base of the cupola, calculated to bear a load of at least 110 tons. This was done and it saved the building (Szabo, 1976). Historically, it was the beginning of constructional engineering, based on modern physics. However, of even greater interest in the context of my article is the psychology accompanying the discussion of which proposal to implement. The "tre mattematici" were defensive. The three monks wrote: "Perhaps we will have to apologize to those who do not only prefer practice to theory but consider practice as exclusively adequate, theory perhaps as detrimental" - but then they defend mathematical methods in the case of St. Peter because of its unique design and dimension. Their opponents, however, were aggressive: anonymous pamphlets were distributed in Rome saying that since Michelangelo had constructed the cupola of St. Peter without mathematics it would also be possible to repair it without any help from mathematics and from those mathematicians.

This is not to suggest that a really serious conflict between theoretical and empirical approaches exists nowadays in developmental biology. We don't hear anything about anti-mathematics pamphleteering. But there are rumors of a milder form of reluctance: stop reading a paper at once if a mathematical equation is encountered. What the story about St. Peter's tells us, in any case, is that skepticism about reasonable applications of mathematics can be a transient phenomenon. In fact, mathematics is useful or 


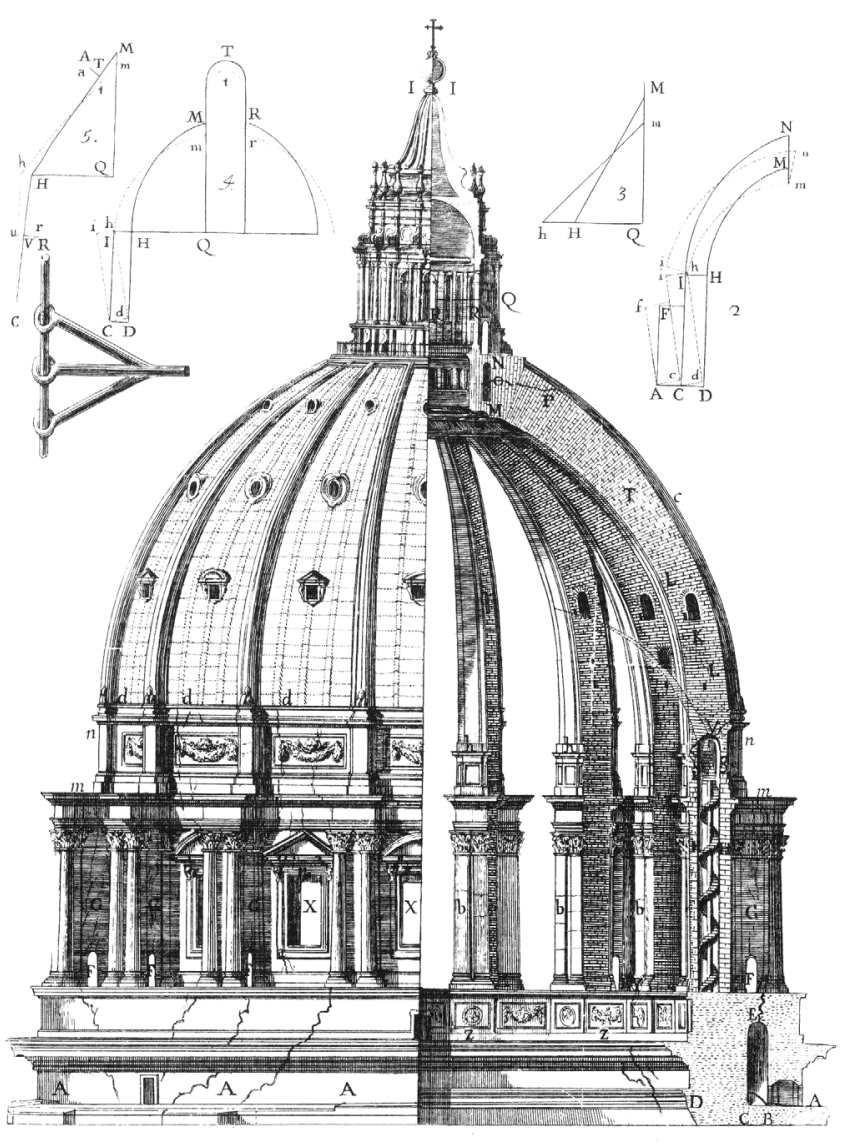

Fig. 12. Damages in the base of the cupola of St. Peter' Basilica in 1743. Drawing in 'Parere di tre mattematici..' by Boscovich, Le Seur and Jaquier (Boscovich et al., 1743). The three monks were pioneers of constructional engineering and forerunners of shell theory. Their mathematical analysis led to successful measures for saving the cupola.

even necessary for solving problems whenever it is better, and more consistent than just words, and this criterion also applies to understanding development.

\section{Hydra - a model for what?}

Let me now come back to our main topic, Hydra as a model system for developmental biology. There have been, and probably still are, distinguished biologists who consider cnidaria a sideline, in itself worthy as a subject of research on their specific evolutionary achievements, yet untypical for the mainstream of evolution of the animal kingdom. I recall a lecture of the admirable Pierre Tardent in 1993 with the title "The Cnidarians - in spite of their highly innovative achievements - an evolutionary dead end".

Perhaps such views also underly the absence of strong responses to a particularly interesting discovery in an earlier phase of Hydra research: In 1909, Ethel Browne demonstrated that a tiny piece of the hypostome of Hydra, transplanted into the body column of another polyp, will induce the formation of a new head. In her beautiful paper (Browne, 1909), she clearly demonstrated with the help of colour markers that there is true induction, namely that it is the host tissue that is induced to form a new body axis.
And yet, these early results received little attention, even after embryonic induction in amphibians was discovered (Spemann and Mangold, 1924). My guess is that her paper was underrated mainly because many biologists, at that time, did not really accept developmental regulation in Hydra tissue as model for embryonic processes in animals.

I am among those who think of Hydraas a model for basic features of biological development. At the phenomenological level, there is very impressive evidence for common features of developmental regulation. At the molecular level, it turns out that spatial patterning, including that of the body plan, involves the same classes of molecules in different organisms. The past decade has provided an ever increasing wealth of comparative molecular information on genes and genomes indicating that basic developmental mechanisms in different organisms are related. Many constituents of pattern forming systems had already evolved at the stage of cnidaria. This applies, for example, to members of the wnt family in Hydra (Lengfeld et al., 2009) and Nematostella (for review, see Technau and Steele, 2011).

However, we should not overlook the fact that identical molecular constituents often participate, depending on the organism, in different developmental functions, including evolutionary novel ones. Moreover, genomes of cnidaria have acquired, in the course of their evolution, many genes without homologs in other species, and such genes may encode species specific features (for review see Khalturin et al., 2009). In other words, the claim "Hydra is a model for biological development and regulation" is correct only if it is not overstressed. Nevertheless it is remarkable to what extent basic features of the development of organisms and their organs can be traced back to early stages of evolution.

In general, progress in understanding development depends on combined evidence from different organisms, and Hydra is one of the rewarding model systems. This applies, in particular, to the interplay of activation and inhibition in biological pattern formation that I have discussed in some detail in this article. After all, it were the spectacular capabilities of Hydra tissue to regenerate that established Hydra as a model for the de-novo generation of biological patterns - capabilities discovered more than two and a half centuries ago by the great pioneer of experimental biology Trembley, by his inspiring friend Reaumur, and by Rösel von Rosenhof, biologist, superb artist, original scientific publisher!

\section{References}

BABLOYANTZ, A., HIERNAUX, J. (1975). Models for cell differentiation and generation of polarity in diffusion governed morphogenetic fields. Bull Math Biol 7: 637-657.

BERKING, S. (1977). Bud formation in Hydra: Inhibition by an endogenous morphogen. Wilhem Roux's Arch Entw Mech 181: 215-225.

BOSCOVICH, R.G., LE SEUR, T., JAQUIER, F. (1743). Parere di tre mattematici sopra i danni, che si sono trovati nella Cupola di S. Pietro sul fine dell'Anno MDCCXLII. Dato per ordine di nostro Signore Papa Benedetto XIV, Rom.

BROWNE, E.N. (1909). The production of new hydranths in hydra by the insertion of small grafts. J Exp Zool 7: 1-37.

DAVID, C.N., GIERER, A. (1974). Cell cycle kinetics and development of Hydra attenuata. III. Nerve and nematocyte differentiation. J Cell Sci 16: 359-375.

GIERER, A. (1977a). Biological features and physical concepts of pattern formation exemplified by hydra. Curr Top Dev Biol 11: 17-59.

GIERER, A. (1977b). Physical aspects of tissue evagination and biological form. $Q$ Rev Biophys 10: 529-593.

GIERER, A. (1981). Generation of biological patterns and form: some physical, 
mathematical, and logical aspects. Prog Biophys Mol Biol 37: 1-47.

GIERER, A., BERKING, S., BODE, H., DAVID, C.N., FLICK, K., HANSMANN, G., SCHALLER, H., TRENKNER, E. (1972). Regeneration of hydra from reaggregated cells. Nature New Biol. 239: 98-101.

GIERER, A., MEINHARDT, H. (1972). A theory of biological pattern formation. Kybernetik 12: 30-39.

GIERER, A., SCHRAMM, G. (1956). Infectivity of ribonucleic acid from tobacco mosaic virus. Nature 177: 702-703.

GOETHE, J.W. (1817). Entdeckung eines trefflichen Vorarbeiters. Morphologische Hefte 1. In Goethe, Die Schriften zur Naturwissenschaft, Vol. 9 (Ed. D. Kuhn, 1954). Böhlaus, Weimar.

GRANERO, M.I., PORATI, A., ZANNACCA, D. (1977). A bifurcation analysis of pattern formation in a diffusion governed morphogenetic field. J Math Biol 4: 21-27.

HARTLINE, H.K., WAGNER, H.G., RATLIFF, F. (1956). Inhibition in the eye of Limulus.. $J$ Gen Physiol 38: 651-673.

HEISENBERG, W. (1969). Der Teil un das Ganze. Piper, Müenchen.

JULESZ, B. (1965). Texture and visual perception. Sci Am 212: 38-48.

KHALTURIN, K., HEMMRICH, G., FRAUNE, S., AUGUSTIN, R., BOSCH, T.C. (2009). More than just orphans: are taxonomically-restricted genes important in evolution? Trends Genet 25: 404-413.

KIRSCHFELD, B., REICHARDT, W. (1964). Die Verarbeitung stationärer optischer Nachrichten im Komplexauge von Limulus. Kybernetik 2: 43-61.

LENGFELD, T., WATANABE, H., SIMAKOV, O., LINDGENS, D., GEE, L., LAW, L., SCHMIDT, H.A., OZBEK, S., BODE, H., HOLSTEIN, T.W. (2009). Multiple Wnts are involved in Hydra organizer formation and regeneration. Dev Bio/330: 186-199.

MEINHARDT, H. (1982). Models of biological pattern formation. Academic Press, London, New York.

MEINHARDT, H. (2003). The algorithmic beauty of sea shells. Springer, Berlin, Heidelberg.

MEINHARDT, H. (2012) Modeling pattern formation in hydra: a route to understanding essential steps in development. Int. J. Dev. Biol. 56: 447-462.
MEINHARDT, H., GIERER, A. (1974). Applications of a theory of biological pattern formation based on lateral inhibition. J Cell Sci 15: 321-346.

MEINHARDT, H., GIERER, A. (2000). Pattern formation by local self-activation and lateral inhibition. Bioessays 22: 753-760.

PAULING, L. (1946). The Nature of the Chemical Bond. Cornell University Press, Cornell.

PAULING, L., COREY, R.B., BRANSON, H.R. (1951). The structure of proteins; two hydrogen-bonded helical configurations of the polypeptide chain. Proc Natl Acad Sci USA 37: 205-211.

RATCLIFF, M. (2012). The Trembley Effect or the birth of marine zoology. Int J Dev Biol 56: 425-436.

RÉAUMUR, R.A. (1741). Animaux coupés et partagés en plusieurs parties, et qui se reproduisent tout entiers dans chacune. Mémoires de l'Académie Royale des Sciences de Paris 9: 75-76.

ROE, S.A. (1982). Matter, life and generation. 18th ce ${ }^{\text {nt }}$ ury embryology and the HallerWolff debate. Cambridge University Press, Cambridge.

RÖSEL VON ROSENHOF, J.A. (1755). Historie der Polypen und anderer kleiner Wasserinsekten, Insektenbelustigungen vol 3. Nürnberg.

SCHALLER, H.C. (1973). Isolation and characterization of a low-molecular-weight substance activating head and bud formation in hydra. $J$ Embryol Exp Morphol 29: 27-38.

SPEMANN, H., MANGOLD, H. (1924). Über die Induktion von Embryonalanlagen durch Implantation artfremder Organisatoren. Wilhem Roux's Arch Entw Mech 100: 599-638.

SZABO, I. (1976). Geschichte dermechanischen Prinzipien. Birkhäuser, Basel Stuttgart.

TECHNAU, U., STEELE, R.E. (2011). Evolutionary crossroads in developmental biology: Cnidaria. Development 138: 1447-1458.

TREMBLEY, A. (1744). Mémoires pour servir à l'histoire d'un genre de polypes d'eau douce, à bras en forme de cornes. Jean \& Herman Verbeek, Leide.

TURING,A. (1952). The chemical basis of morphogenesis. Phil Trans R Soc B237:32-72.

WOLFF, C.F. (1759). Theoria Generationis. Dissertation Halle. 


\section{Further Related Reading, published previously in the Int. J. Dev. Biol.}

Dynamical patterning modules: a "pattern language" for development and evolution of multicellular form Stuart A. Newman and Ramray Bhat

Int. J. Dev. Biol. (2009) 53: 693-705

Principles of branch formation and branch patterning in Hydrozoa

Stefan Berking

Int. J. Dev. Biol. (2006) 50: 123-134

From observations to paradigms; the importance of theories and models. An interview with Hans Meinhardt

Richard Gordon and Lev Beloussov

Int. J. Dev. Biol. (2006) 50: 103-111

Cnidarians as a model system for understanding evolution and regeneration.

Brigitte Galliot and Volker Schmid

Int. J. Dev. Biol. (2002) 46: 39-48

Multiple axon guidance cues establish the olfactory topographic map: how do these cues interact?

James A St John, Heidi J Clarris and Brian Key

Int. J. Dev. Biol. (2002) 46: 639-647

Models of biological pattern formation: common mechanism in plant and animal development. $\mathrm{H}$ Meinhardt

Int. J. Dev. Biol. (1996) 40: 123-134

5 yr ISI Impact Factor $(2010)=2.961$

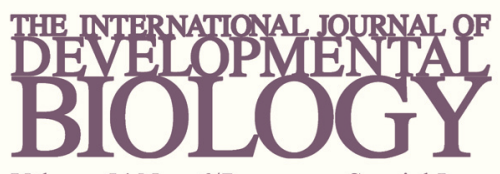

Volume 54 Nos. 6/7

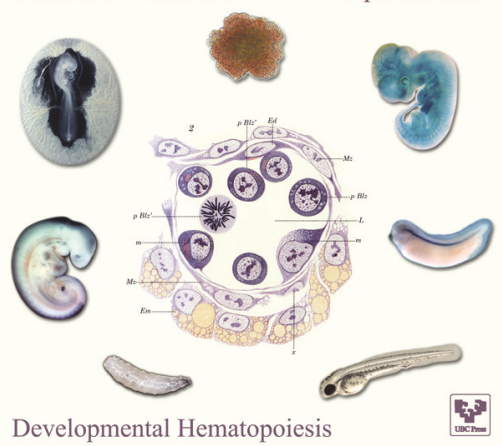

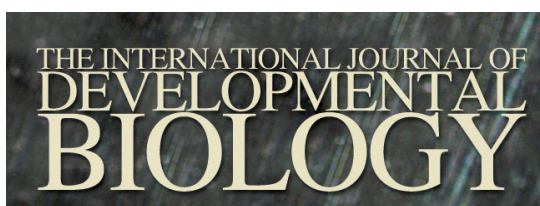

Volume 56 Nos. $1 / 2 / 3 \quad$ Special Issue

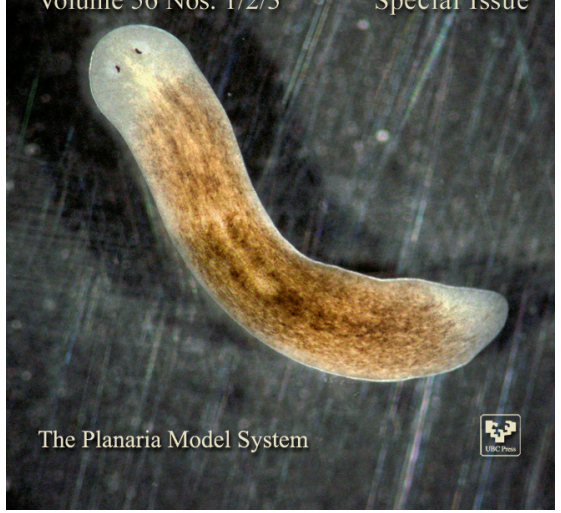

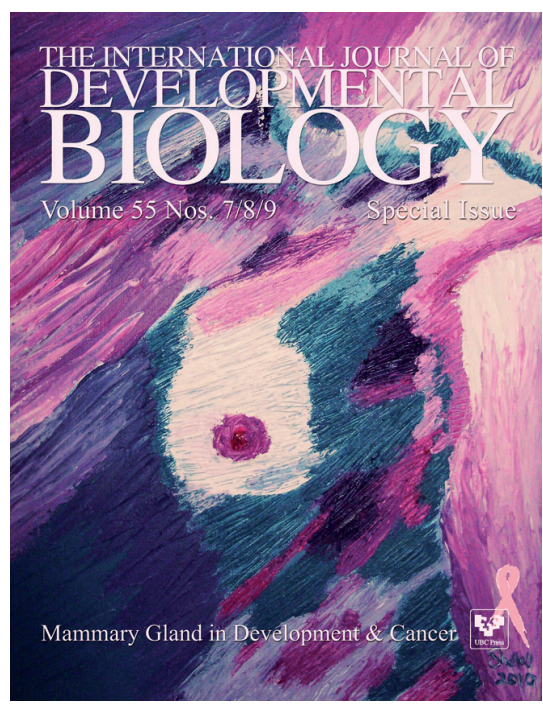

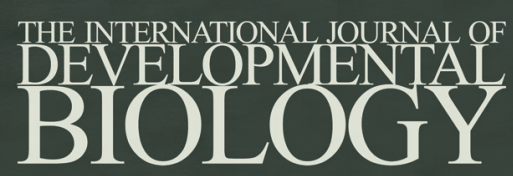

Volume 55 Nos. $4 / 5$

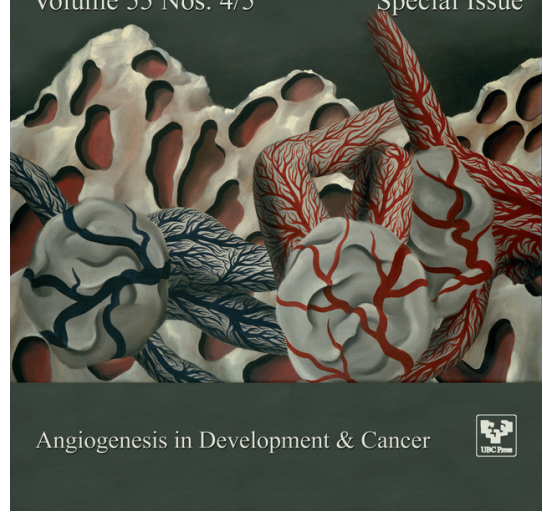

